\title{
The effectiveness of tobacco control policies on vulnerable populations in the USA: a review
}

\author{
Maya Vijayaraghavan, ${ }^{1}$ Steven A Schroeder, ${ }^{2}$ Margot Kushel ${ }^{1}$
}

\begin{abstract}
${ }^{1}$ Division of General Internal Medicine, University of California, San Francisco, Zuckerberg San Francisco General Hospital,

San Francisco, California, USA ${ }^{2}$ Division of General Internal Medicine, University of California, San Francisco, California, USA

Correspondence to Dr Maya Vijayaraghavan, Division of General Internal Medicine/San Francisco General Hospital, University of California, San Francisco, UCSF Box 1364, 1001 Potrero Avenue, San Francisco 94110, California, USA; Maya. Vijayaraghavan@ucsf.edu
\end{abstract}

Received 21 April 2016 Revised 24 June 2016 Accepted 27 August 2016 Published Online First 22 September 2016

\begin{abstract}
Despite population-wide efforts to reduce tobacco use, low-income populations in the USA have much higher rates of tobacco use compared with the general population. The principal components of tobacco control policies in the USA include cigarette taxes, clean indoor air laws and comprehensive interventions to increase access to tobacco cessation services. In this review, we describe the effectiveness of these policies and interventions in reducing tobacco use among vulnerable populations, focusing on persons with mental health disorders and substance use disorders, persons who have experienced incarceration or homelessness, and low-income tenants of public housing. We discuss the challenges that evolving tobacco and nicotine products pose to tobacco control efforts. We conclude by highlighting the clinical implications of treating tobacco dependence in healthcare settings that serve vulnerable populations.
\end{abstract}

\section{INTRODUCTION}

With the success of population-wide public health efforts over the past four decades, the prevalence of tobacco use has declined significantly in the general population. In 2015, the prevalence of tobacco use reached a modern low of $15.4 \%$ in the USA. ${ }^{1}$ However, prevalence remains high in vulnerable populations. Tobacco use among vulnerable populations including individuals experiencing incarceration or homelessness, persons who have severe mental illness and/or substance use disorders, persons who belong to racial/ethnic minorities or gender or sexual minorities is to 3-5 times higher than the general population. ${ }^{2-6}$

Tobacco-related health disparities contribute significantly to increased morbidity and mortality in these vulnerable populations. The most common causes of death among people in prison in the USA are tobacco-induced diseases: lung cancer, ischaemic heart disease, other heart disease, cerebrovascular disease and chronic lung disease. ${ }^{7}$ The age-adjusted smoking-related mortality and years of potential life lost is much higher among persons experiencing incarceration than those in the general population. ${ }^{7}$ In the homeless population, tobacco-related chronic diseases are among the leading causes of death. ${ }^{8}{ }^{9}$ Tobacco-attributable deaths contribute to about a quarter of the total deaths among those aged 50 years and older, and about half of the total substance-related deaths in the homeless populations. ${ }^{10}$ About half of the 444000 deaths from tobacco use in the USA are among persons with mental health and substance use disorders. ${ }^{3}$ Persons with substance use disorders are more likely to die from tobacco-related diseases than of drug-related or alcohol-related causes. ${ }^{11}$

To meet the Healthy People 2020 goals of reducing tobacco use to $<12.0 \%$ nationally, ${ }^{12}$ the prevalence of tobacco use needs to decline substantially among vulnerable populations. Population-wide public health efforts such as cigarette taxes and clean indoor air laws has been highly effective in reducing tobacco use in the general population by reducing initiation and increasing cessation. ${ }^{13}{ }^{14}$ Clinical interventions that include the provision of behavioural counselling and pharmacotherapy have also been effective in reducing tobacco use in the general population. ${ }^{15}$ These public health and clinical interventions also work in vulnerable populations, with varying success.

In this review, we examine the effectiveness of tobacco control policies including cigarette taxes and clean indoor air laws on reducing tobacco use in vulnerable populations. We discuss the efficacy of tobacco cessation policies to increase access to tobacco dependence services among vulnerable populations. We highlight the challenges that emerging tobacco and nicotine products pose to reducing tobacco use among vulnerable populations. We conclude by highlighting clinical implications of treating tobacco dependence in healthcare settings serving vulnerable populations.

\section{CIGARETTE TAXES}

Tobacco taxation to raise cigarette prices is one of the most effective population-based strategies to decrease cigarette-smoking prevalence. ${ }^{16-18}$ High cigarette pack price reduces consumption and the overall prevalence of tobacco use by promoting reduction and cessation among current smokers and uptake by youth and young adults in the USA. ${ }^{16}{ }^{19}$ Economic theory suggests that raising cigarette prices should reduce consumption more in lower income than higher income smokers because lower income smokers are more price sensitive. ${ }^{16-23}$ However, studies have shown varying responses to price increases among low-income populations. Individuals may compensate for higher prices by relying on low-priced cigarette products (eg, bootlegged or smuggled cigarette products), foregoing other essential goods ${ }^{24-28}$ or reducing consumption. ${ }^{23} 2930$ Critics raise concerns that cigarette taxes are regressive because they disproportionately affect low-income smokers who smoke more and also devote a higher percentage of their income towards purchasing tobacco. ${ }^{31} 32$ However, several studies have shown that high cigarette prices are associated with reduced consumption equally among low-income and higher income smokers, ${ }^{23} 2930$ and that price increases over time 
are associated with decreased population-wide smoking prevalence. ${ }^{33} 34$ These studies also address the equity implications around increasing cigarette prices for low-income smokers. Studies that recommend a price increase suggest that revenue from cigarette excise taxes should be directed towards cessation programmes that help low-income smokers quit as well as programmes that alleviate their financial burden. ${ }^{29} 3135$ But in actual practice, that rarely happens, as states elect to use the funds for other purposes.

Despite the progress made with taxing cigarettes, the tobacco industry has capitalised on a loophole in the federal statutory definition of cigarettes by evading federal taxes on little cigars, a combustible tobacco product packaged and marketed as cigarettes. ${ }^{36}$ Little cigars are cheaper than cigarettes and are used commonly among low-income populations and youth in the USA. ${ }^{37}{ }^{38}$ Under the current federal tax rates, this loophole costs the USA almost $\$ 130$ million in lost revenue from cigarette smokers who switch to the cheaper and lower-taxed little cigars. ${ }^{39}$ A second loophole involves another law enacted in 2009 that gave the Food and Drug Administration (FDA) regulatory authority over tobacco products. Under this law, the FDA banned candy and fruit-flavoured cigarettes but not cigars or menthol-flavoured cigarettes. ${ }^{39}$ As a result, the use of flavoured cigar products has increased substantially among youth/young adult populations. ${ }^{40-42}$ The cooling and anaesthetic effects of menthol mask the harshness of tobacco smoking, making it appealing to young adults and certain racial/ethnic minority groups. ${ }^{43}$ Menthol cigarettes are heavily marketed to African/ American populations who bear a disproportionate burden of tobacco-related morbidity and mortality. ${ }^{44}$ Possible ways to close the 'little cigar' and menthol cigarette loophole are to tax all tobacco products at the same rate as cigarettes and to extend the ban of flavoured cigarettes to menthol cigarettes and other tobacco products. This measure could lead to decreased initiation of tobacco use by a substantial proportion of the youth, young adult and racially/ethnically diverse low-income populations in the USA.

\section{CLEAN INDOOR AIR LAWS}

Exposure to tobacco smoke is a major environmental hazard, responsible for over 41000 deaths among non-smokers and 400 deaths among infants each year and approximately $\$ 5.6$ billion dollars annually in lost productivity in the USA. ${ }^{45-48}$ Since the surgeon general's first report on the harms of secondhand smoke (SHS) exposure in $1986,{ }^{49}$ significant progress has been made in implementing comprehensive smoke-free policies in all enclosed public places and workplaces, including bars, restaurants and public transportation. ${ }^{50}$ California was the first state to ban smoking in the workplace in 1988, and since then 26 states have implemented comprehensive smoke-free laws. ${ }^{51}$ With growing awareness of the harms of SHS exposure, other settings that serve populations disproportionately affected by tobacco use have implemented smoke-free policies. We describe below the experiences of correctional facilities, psychiatric hospital, substance use recovery programmes, homeless shelters and public housing in implementing smoke-free policies.

\section{Correctional facilities}

Until recently, tobacco use was rooted in the culture of correctional facilities. ${ }^{52-54}$ Requests by non-smoking inmates to live in smoke-free environments and the increasing healthcare costs of incarcerated individuals led the Federal Bureau of Prisons and State Departments of Corrections to recommend tighter smoking restrictions. ${ }^{55}{ }^{56}$ Sequential surveys of federal and state prison systems between 1986 and 2007 showed gradual changes towards increased smoking restrictions. The proportion of prisons that distributed free tobacco to inmates decreased from 53\% in 1986 to none in 2007, and the proportion with smokefree living areas and campus-wide bans increased. 555758 By $2007,96 \%$ of prison systems offered smoke-free living areas and $60 \%$ had enacted campus-wide bans. ${ }^{55} 5758$

Policies were associated with reductions in SHS exposure in prison, ${ }^{59} 60$ and reductions in mortality from smoking-related causes. ${ }^{7}$ There were significant reductions in cancer-related mortality among the US prison populations where bans were effective for over 9 years. ${ }^{7}$ Although few prisons/jails reported violations of policies, those that had enforcement policies and that restricted access to contraband tobacco were most successful in implementing smoke-free policies. ${ }^{60}$ Most individuals who smoked prior to being incarcerated continued to smoke illegally under bans, ${ }^{53} 6162$ though fewer cigarettes than prior. ${ }^{53} 6162$ Few individuals quit completely, and those who did relapsed back to smoking after release. ${ }^{6163}$

\section{Psychiatric hospitals}

Similar to correctional facilities, smoking was part of the culture of psychiatric facilities. In 1991, The Joint Commission on Accreditation of Healthcare Organizations (JCAHO) required all of its accredited hospitals, with the exception of psychiatric hospitals, to ban indoor smoking. ${ }^{64}$ However, over the past two decades most psychiatric hospitals have voluntarily implemented indoor smoke-free policies. A survey in 1993 found that 88.1\% of participating JCAHO accredited psychiatric hospitals, and general hospitals with psychiatric units were adherent to indoor smoking bans. ${ }^{65}$ In 2009, 26\% of these institutions reported campus-wide bans, and 14\% reported plans to adopt such a policy. ${ }^{66}$ Sharing a common regulatory organisation made it possible for psychiatric facilities to implement bans. ${ }^{67}$

Among inpatient psychiatric facilities bans were associated with reduced exposure to SHS, ${ }^{68-70}$ but effects on cessation were mixed. While some studies found that patients in facilities with bans expressed high rates of intention to quit smoking and increased confidence in staying abstinent after discharge, ${ }^{71} 72$ other studies found no association with cessation. ${ }^{69}$ This may be due to inconsistent access to pharmacotherapy and behavioural counselling for tobacco dependence during the hospitalisation, lack of smoking cessation resources after discharge, or increased nicotine dependence and co-occurring substance use disorders during hospitalisation. ${ }^{69}{ }^{73-75}$ The majority of smokers resumed smoking after discharge from a smoke-free psychiatric hospitalisation even when offered nicotine replacement therapy during the hospitalisation. ${ }^{76}$

\section{Addiction treatment centres}

Over the past two decades, many State Substance Abuse Agencies have prioritised treatment of tobacco dependence in state-certified addiction treatment facilities. ${ }^{77-81}$ In 2010,41 of the 50 US states had policies restricting indoor smoking in statecertified treatment facilities. ${ }^{77}$ In a recent study of nationally representative random sample of 1026 substance use recovery programmes in the USA, $98.1 \%$ had an indoor ban and $32.5 \%$ had a total outdoor ban on smoking for patients, employees and visitors. $^{82}$ Of these state programmes, New Jersey and New York's tobacco policies are among the most comprehensive. In 2001, New Jersey implemented a tobacco control policy that included smoking bans in indoor and outdoor areas, required staff to assess clients for tobacco use and mandated treatment for tobacco dependence for both staff and clients. ${ }^{78} 83$ 
However, adherence to the policies varied among treatment programmes. ${ }^{78} 83$ The New York state tobacco control policy, implemented in 2008, required all 1000 of its state-certified addiction treatment facilities to implement $100 \%$ tobacco-free grounds and provide cessations services to their clients. ${ }^{79}$ Within 1 year of implementation, the prevalence of tobacco use among clients in 10 randomly selected New York programmes decreased from $69.4 \%$ to $62.8 \%{ }^{84}$ A 5 -year evaluation of the New York policy in a random selection of five addiction treatment programmes demonstrated that the policy was associated with reduced prevalence of tobacco use among staff and reduced consumption among clients. ${ }^{85}$ The policy was also associated with increased awareness of tobacco addiction among clients. $^{85}$

\section{Homeless shelters}

Unlike correctional facilities, psychiatric hospitals and addiction treatment programmes where there are national data on the prevalence of smoking bans, there are no such data for homeless shelters. Recent data from California and Texas suggest that homeless shelters do have indoor smoke-free policies. An early study conducted in 2005 that focused on long-term transitional homeless shelters in Los Angeles, California, found that 75\% reported an indoor 'no smoking' policy and 78\% reported designated smoking areas. ${ }^{86} \mathrm{~A}$ recent cross-sectional study, conducted in 2012 in Dallas, Texas, among sheltered homeless adults who were staying in a shelter that had an indoor ban and a partial outdoor ban showed that most participants supported the creation of an outdoor smoke-free zone, but not a complete shelter-wide smoking ban. ${ }^{87}$ The ban was associated with decreases in consumption but was not associated with quitting. ${ }^{87}$ Three other recent studies, conducted between 2013 and 2015, focused on homeless clientele of emergency and transitional homeless shelters in San Diego, California. A crosssectional survey of homeless shelters in San Diego County showed that all facilities had an indoor ban on smoking, $61.5 \%$ had an outdoor designated smoking zone and $25 \%$ had a campus-wide ban on smoking. ${ }^{88}$ In two cross-sectional studies of sheltered homeless adults, the majority of participants were supportive of indoor smoke-free policies. ${ }^{89} 90$ In a shelter that had an indoor and outdoor smoking ban, most homeless adults reported reductions in consumption, and about half reported either having made a quit attempt or getting ready to quit completely. ${ }^{90}$

\section{Public housing}

Approximately half the population in the USA is protected by federal, state and local smoke-free policies; however, an estimated 58 million residents, including 15 million children aged 3-11 are exposed to SHS. ${ }^{48}$ Exposure to SHS is disproportionately concentrated among children, persons living in poverty and those who belong to racial/ethnic minorities. ${ }^{48}$ The home is the primary contributor of SHS exposure among children. ${ }^{48}$

In response to the high rates of SHS exposure among nonsmoking tenants of public housing, the Federal Department of Housing and Urban Development's (HUD) Office of Public and Indian Housing issued memorandums in 2009 and 2012 that 'strongly encouraged' public housing authority (PHA) housing ${ }^{91}$ to implement non-smoking policies in some or all of their public housing units. ${ }^{92} 93$ In 2015, HUD proposed to extend the voluntary rule to a mandatory rule that required every PHA to implement smoke-free policies that prohibited use of combustible tobacco in all living units, indoor common areas of PHA buildings and in PHA administrative office buildings. ${ }^{94}$
They also required that the policy extend to all outdoor areas within 25 feet of housing and administrative offices. ${ }^{94}$ PHAs were encouraged to partner with state and local health departments to increase access to cessation resources for smoking tenants of public housing. The enactment of this rule is contingent upon reviewing public commentaries on the advantages and disadvantages of the ruling.

Public housing includes 3100 PHA housing, representing 1.2 million housing units across the country. In September 2015, there were over 228000 units that were smoke-free. ${ }^{95}$ If the proposed rule were to become effective, it would affect over 940000 housing units, including 500000 households with elderly individuals or persons with disabilities and over 760000 households with children. ${ }^{95}$

Studies describing preferences for smoke-free policies among low-income tenants of subsidised housing have found that the majority supported such policies, but differences existed by smoking status. ${ }^{96-98}$ Not surprisingly, non-smokers and never smokers were more likely to support smoke-free policies compared with smokers. ${ }^{96-98}$ Smokers who had an intention to quit smoking within the next 6 months were more likely to support smoke-free policies in indoor living areas compared with those without an intention to quit. ${ }^{97}$ In 2012, the Boston Housing Authority (BHA) implemented a comprehensive smoke-free policy restricting smoking in indoor units, becoming the largest housing authority to do so at that time. Studies among BHA tenants have found overall support for the policy, but dissatisfaction with lack of enforcement. ${ }^{99}$ The few studies that have examined cessation behaviours among public housing tenants exposed to smoke-free policies have found reduced consumption and increased quit rates among smokers. ${ }^{100}$

\section{Smoke-free homes}

Related to smoke-free policies in public housing, the voluntary adoption of smoke-free homes is a strong indicator of antitobacco norms. ${ }^{101}$ Strong clean indoor air laws are associated with increased adoption of smoke-free homes among smokers and non-smokers. ${ }^{102} 103$ The western part of the USA, with its strong antitobacco norms, has among the highest prevalence of households with smoke-free homes. ${ }^{104}$ Smoke-free homes have been associated with reduced exposure to SHS among nonsmokers and reduced smoking behaviours among low-income and higher income smokers. ${ }^{29} 101105{ }^{106}$ Low-income adults are less likely than higher income adults to adopt smoke-free homes, ${ }^{29} 107108$ reflecting differential smoking norms in the respective communities. Despite this, brief interventions have been shown to increase adoption of smoke-free homes in lowincome households. ${ }^{109}$

\section{Electronic nicotine delivery systems and threats to clean indoor air laws}

The surge in the use of Electronic Nicotine Delivery Systems (ENDS), of which electronic cigarettes are the most common form, has the potential to renormalise tobacco use and pose a significant threat to the efficacy and effectiveness of clean indoor air laws in reducing tobacco prevalence. Electronic cigarettes are battery-operated devices that release aerosolised nicotine. Evidence to date has suggested that the aerosol released by electronic cigarettes can be harmful. ${ }^{110}$ The evidence around the use of ENDS is equivocal for aiding cessation. ${ }^{111-116}$ Prior to the federal regulation on the use of ENDS, state governments regulated the use of electronic cigarettes. As of November 2014, 40 states had prohibited the sales of ENDS to minors, but only 3 states prohibited the use of ENDS in private worksites, 
restaurants or bars (New Jersey, North Dakota and Utah). ${ }^{117}$ Only three states (Pennsylvania, Nevada and Texas) did not have statewide laws prohibiting ENDS sales to minors or restricting indoor use of ENDS. ${ }^{117}$ In 2016, the FDA finalised a rule that extended their regulatory authority to cover all tobacco products, including vaporisers, vape pens, hookah pens, electronic cigarettes, e-pipes and all other ENDS. ${ }^{118}$ This regulatory authority allows the FDA to regulate the manufacture, import, packaging, labelling, advertising, promotion, sale and distribution of ENDS. The final rule will require that all manufacturers, importers and retailers register product listings with the FDA; report ingredients, and potentially harmful constituents; and place health warnings on the packages. There are also several provisions to restrict sales to minors including not allowing sales to persons $<18$ years of age, requiring age verification by photo ID, not allowing the sales of these products in vending machines and not allowing the free distribution of samples.

\section{TOBACCO CESSATION POLICIES}

Approximately a third of Medicaid enrolees are smokers. Healthcare costs from smoking-related chronic diseases place a huge burden on Medicaid, the largest public health insurance programme in the USA. ${ }^{119}{ }^{120}$ An estimated $15 \%$ of all Medicaid expenditures, or $\$ 10$ billion annually, are attributable to smoking. ${ }^{119} 121$ Previous research has shown that state Medicaid programmes could reduce smoking prevalence, smoking-related morbidity and smoking-related costs among Medicaid enrolees by covering FDA approved cessation treatments and by eliminating barriers to accessing treatment. ${ }^{122-124}$

The 2010 Patient Protection and Affordable Care Act (ACA) requires that all state Medicaid programmes cover all seven FDA-approved medications for cessation and individual, group or telephone counselling services for at least two quit attempts per year, without patient cost sharing or prior authorisation. ${ }^{125}$ Despite these provisions in the ACA, variations exist in the implementation of coverage across states. In a survey of state Medicaid coverage conducted by the American Lung Association between August 2014 and June 2015, only nine states offered all the seven FDA-approved medications for cessation and smoking cessation. ${ }^{126}$ However, all nine states had some barriers to treatments including copayments or prior authorisation requirements. ${ }^{126}$ Thirty-one states covered individual counselling, 10 states covered group counselling and 30 states covered all seven medications for cessation. ${ }^{126}$ However, common barriers included prior authorisation requirements, annual limits on quit attempts, limits on duration and required copayments. ${ }^{126}$

In 2013, only $10 \%$ of Medicaid enrolees who were smokers had received cessation medications, and most states spent significantly less on cessation medications in comparison with the estimated cost to Medicaid from smoking-related diseases. ${ }^{120}$ Disparities in smoking prevalence and use of state Medicaid cessation resources were greatest among non-expansion Medicaid states (19 states have not adopted the ACA Medicaid expansion) compared with those that expanded Medicaid eligibility. ${ }^{120}$

\section{CONCLUSIONS}

Describe ways in which healthcare systems, healthcare providers and public health practitioners can improve delivery of cessation services among vulnerable populations?

Although cigarette smoking has declined over the past four decades, prevalence remains very high among vulnerable populations. Helping individuals quit smoking and preventing youth from initiating smoking should be a top health priority for all healthcare providers. To achieve the Healthy People 2020 goal of reducing the national prevalence of tobacco use to $<12 \%$, there needs to be a concerted effort among individual providers, clinics, hospitals and healthcare systems to minimise barriers to access to cessation aids for vulnerable populations and to counsel all smokers and non-smokers living with smokers to implement voluntary home smoking restrictions. In addition to these clinical interventions, public health approaches such as increasing access to smoke-free public housing and smoke-free public spaces, legislative restrictions that restrict sales of evolving tobacco and nicotine products to youth and young adults, and tobacco price increases will help to further reduce tobacco use among vulnerable populations.

\section{Main messages}

- Despite population-wide efforts to reduce tobacco use, vulnerable populations in the USA have much higher rates of tobacco use compared with the general population.

- Exposure to secondhand smoke is disproportionately concentrated among children, persons living in poverty and those who belong to racial/ethnic minorities.

- Tobacco-related chronic diseases are among the leading causes of morbidity and mortality among vulnerable populations in the USA.

- Efforts to reduce tobacco use among vulnerable populations should include ensuring access to cessation services for all smokers and increasing exposure to comprehensive smoke-free policies for all smokers and non-smokers.

\section{Current research questions}

- Describe three major tobacco control policies that have reduced the prevalence of tobacco use in the USA?

- Describe the effects of raising cigarette prices on tobacco use and cessation behaviours among vulnerable populations?

- What are some of the effects of smoke-free policies and smoke-free homes on tobacco use and cessation behaviours?

- Describe ways in which healthcare systems, healthcare providers and public health practitioners can improve delivery of cessation services among vulnerable populations?

- Describe some of the evolving tobacco and nicotine products and the challenges they pose to tobacco control?

\section{Key references}

- Schroeder SA, Morris CD. Confronting a neglected epidemic: tobacco cessation for persons with mental illnesses and substance abuse problems. Annu Rev Public Health 2010;31:297-314, 291p following 314.

- Binswanger IA, Carson EA, Krueger PM, et al. Prison tobacco control policies and deaths from smoking in United States prisons: population based retrospective analysis. BMJ 2014;349:4542. 
- U.S. Department of Health and Human Services. The Health Consequences of Smoking - 50 Years of Progress: A Report of the Surgeon General, 2014. Atlanta, GA: http://www. surgeongeneral.gov/library/reports/50-years-of-progress/ (accessed 21 Apr 2016).

- Clinical Practice Guideline Treating Tobacco Use and Dependence 2008 Update Panel, Liaisons, and Staff. A clinical practice guideline for treating tobacco use and dependence: 2008 update. A U.S. Public Health Service report. Am J Prev Med. 2008;35:158-76.

- Homa DM, Neff LJ, King BA, et al. Vital signs: disparities in nonsmokers' exposure to secondhand smoke_-USA, 19992012. MMWR Morb Mortal Wkly Rep 2015;64:103-108.

\section{Self assessment questions}

Please answer true or false to the below statements.

1. Tobacco use in the USA is disproportionately concentrated among vulnerable populations including persons with severe mental illness and/or substance use disorders, and persons who have experienced incarceration or homelessness.

2. Raising cigarette taxes has been shown to reduce consumption among low-income and higher income smokers, and reduce initiation of tobacco use among youth.

3. Comprehensive smoke-free policies are associated with declines in the prevalence of smoking at the community and population level.

4. Smoke-free homes have been shown to reduce consumption, increase successful quitting and reduce relapse to smoking among smokers.

5. Under the Affordable Care Act, Medicaid is mandated to cover tobacco dependence treatment services that include all seven FDA-approved medications for cessation as well in-person and telephone counselling.

6. Despite these provisions in the Affordable Care Act, variations exist in the implementation of coverage across states.

Contributors MV participated in the design, concept, drafting and the revision of the manuscript. SAS and MK participated in the design, concept and the revision of the manuscript. Each of the authors has approved the final manuscript.

Competing interests None declared.

Provenance and peer review Commissioned; externally peer reviewed.

\section{REFERENCES}

1 Jamal A, Agaku IT, O'Connor E, et al. Current cigarette smoking among adultsUnited States, 2005-2013. MMWR Morb Mortal Wkly Rep 2014;63:1108-12.

2 Richter KP, Ahluwalia HK, Mosier MC, et al. A population-based study of cigarette smoking among illicit drug users in the United States. Addiction 2002;97:861-9.

3 Schroeder SA, Morris CD. Confronting a neglected epidemic: tobacco cessation for persons with mental illnesses and substance abuse problems. Annu Rev Public Health 2010;31:297-314, 291p following 314.

4 Barbeau EM, Krieger N, Soobader MJ. Working class matters: socioeconomic disadvantage, race/ethnicity, gender, and smoking in NHIS 2000. Am J Public Health 2004;94:269-78.

5 Kalman D, Morissette SB, George TP. Co-morbidity of smoking in patients with psychiatric and substance use disorders. Am J Addict 2005;14:106-23.

6 Centers for Disease Control and Prevention. Vital signs: current cigarette smoking among adults age $\geq 18$ years—United States, 2005-2010. MMWR Morb Mortal Wkly Rep. 2011;60:1207-12.
7 Binswanger IA, Carson EA, Krueger PM, et al. Prison tobacco control policies and deaths from smoking in United States prisons: population based retrospective analysis. BMJ 2014;349:g4542.

8 Baggett TP, Hwang SW, O'Connell JJ, et al. Mortality among homeless adults in Boston: shifts in causes of death over a 15-year period. JAMA Intern Med 2013:173:189-95.

9 Hwang SW, Wilkins R, Tjepkema M, et al. Mortality among residents of shelters, rooming houses, and hotels in Canada: 11 year follow-up study. BMJ 2009:339: b4036.

10 Baggett TP, Chang Y, Singer DE, et al. Tobacco-, alcohol-, and drug-attributable deaths and their contribution to mortality disparities in a cohort of homeless adults in Boston. Am J Public Health 2015;105:1189-97.

11 Hurt RD, Offord KP, Croghan IT, et al. III. Mortality following inpatient addictions treatment. Role of tobacco use in a community-based cohort. JAMA 1996;275:1097-103

12 Healthy People 2020: Tobacco Use. https://www.healthypeople.gov/2020/ topics-objectives/topic/tobacco-use. (accessed 21 Apr 2016).

13 Pierce JP, Gilpin EA, Emery SL, et al. Has the California tobacco control program reduced smoking? JAMA 1998;280:893-9.

14 Pierce JP, White VM, Emery SL. What public health strategies are needed to reduce smoking initiation? Tob Control 2012;21:258-64.

15 Clinical Practice Guideline Treating Tobacco Use and Dependence 2008 Update Panel, Liaisons, and Staff. A clinical practice guideline for treating tobacco use and dependence: 2008 update. A U.S. Public Health Service report. Am J Prev Med 2008;35:158-76.

16 Bader P, Boisclair D, Ferrence R. Effects of tobacco taxation and pricing on smoking behavior in high risk populations: a knowledge synthesis. Int J Environ Res Public Health 2011;8:4118-39.

17 Chaloupka FJ, Tauras JA. The power of tax and price. Tob Control 2011:20:391-2.

18 Ross $\mathrm{H}$, Blecher $\mathrm{E}$, Yan $\mathrm{L}$, et al. Do cigarette prices motivate smokers to quit? New evidence from the ITC survey. Addiction 2011;106:609-19.

19 Ekpu VU, Brown AK. The economic impact of smoking and of reducing smoking prevalence: review of evidence. Tob Use Insights 2015;8:1-35.

20 Ahrens D. Tobacco taxes and cigarette consumption in low income populations. Am J Public Health 2009;99:6.

21 Farrelly MC, Bray JW, Pechacek T, et al. Response by adults to increases in cigarette prices by sociodemographic characteristics. Southern Econ J 2001;68:156-65.

22 Murphy JM, Shelley D, Repetto PM, et al. Impact of economic policies on reducing tobacco use among Medicaid clients in New York. Prev Med 2003;37:68-70.

23 Dinno A, Glantz $\mathrm{S}$. Tobacco control policies are egalitarian: a vulnerabilities perspective on clean indoor air laws, cigarette prices, and tobacco use disparities. Soc Sci Med 2009;68:1439-47.

24 Licht AS, Hyland AJ, O'Connor RJ, et al. Socio-economic variation in price minimizing behaviors: findings from the International Tobacco Control (ITC) Four Country Survey. Int I Environ Res Public Health 2011;8:234-52.

25 Lee JM, Chen SH, Chen HF, et al. Price sensitivity and smoking smuggled cigarettes. Eur J Public Health 2009;19:23-7.

26 Farrelly MC, Nimsch CT, Hyland A, et al. The effects of higher cigarette prices on tar and nicotine consumption in a cohort of adult smokers. Health Econ 2004:13:49-58.

27 Shelley D, Cantrell MJ, Moon-Howard J, et al. The $\$ 5$ man: the underground economic response to a large cigarette tax increase in New York City. Am J Public Health 2007:97:1483-8.

28 Hyland A, Higbee C, Bauer JE, et al. Cigarette purchasing behaviors when prices are high. J Public Health Manag Pract 2004;10:497-500.

29 Vijayaraghavan M, Messer K, White MM, et al. The effectiveness of cigarette price and smoke-free homes on low-income smokers in the United States. Am J Public Health 2013;103:2276-83.

30 Siahpush M, Wakefield MA, Spittal MJ, et al. Taxation reduces social disparities in adult smoking prevalence. Am J Prev Med 2009;36:285-91.

31 Farrelly MC, Nonnemaker JM, Watson KA. The consequences of high cigarette excise taxes for low-income smokers. PLOS ONE 2012;7:e43838.

32 Franks $P$, Jerant $A F$, Leigh JP, et al. Cigarette prices, smoking, and the poor: implications of recent trends. Am J Public Health 2007:97:1873-7.

33 Warner KE. The economics of tobacco: myths and realities. Tob Control 2000:9:78-89.

34 Centers for Disease Control and Prevention. State Cigarette Excise Taxes-United States, 2009. MMWR Morb Mortal Wkly Rep 2010;59:385-8.

35 Wilson N, Thomson G. Tobacco taxation and public health: ethical problems, policy responses. Soc Sci Med 2005;61:649-59.

36 Legacy Foundation. Tobacco fact sheet Cigars, Cigarillos and Little cigars, Tobacco fact sheet Cigars, Cigarillos and Little cigars. http://www2.aap.org/richmondcenter/ pdfs/Cigars.pdf (accessed 21 Apr 2016)

37 Vijayaraghavan $\mathrm{M}$, Pierce JP, White $\mathrm{M}$, et al. Differential use of other tobacco products among current and former cigarette smokers by income level. Addict Behav 2014;39:1452-8. 
38 Richardson A, Rath J, Ganz 0, et al. Primary and dual users of little cigars/ cigarillos and large cigars: demographic and tobacco use profiles. Nicotine Tob Res 2013;15:1729-36.

39 Tobacco Free Kids. 'The rise of cigar smoking and cigar-smoking harms'. https:/l www.tobaccofreekids.org/research/factsheets/pdf/0333.pdf (accessed 21 Apr 2016).

40 Regan AK, Dube SR, Arrazola R. Smokeless and flavored tobacco products in the U.S.: 2009 Styles survey results. Am J Prev Med 2012;42:29-36.

41 Arrazola RA, Dube SR, Engstron M. Current tobacco use among middle and high school students-United States, 2011. MMWR-Morbidity and Mortality Reports 2012;61:581-5

42 King BA, Tynan MA, Dube SR, et al. Flavored-little-cigar and flavored-cigarette use among U.S. middle and high school students. J Adolesc Health 2014;54:40-6.

43 Yerger VB. Menthol's potential effects on nicotine dependence: a tobacco industry perspective. Tob Control 2011;20(Suppl 2):ii29-36.

44 Okuyemi KS, Faseru B, Sanderson Cox L, et al. Relationship between menthol cigarettes and smoking cessation among African American light smokers. Addiction 2007;102:1979-86.

45 Barnoya J, Glantz SA. Cardiovascular effects of secondhand smoke: nearly as large as smoking. Circulation 2005;111:2684-98.

46 Moritsugu KP. The 2006 Report of the Surgeon General: the health consequences of involuntary exposure to tobacco smoke. Am J Prev Med 2007;32:542-3.

47 California Environmental Protection Agency, Office of Environmental Health Hazard Assessment. Proposed Identification of Environmental Tobacco Smokes as a toxic air contaminant. http://oehha.ca.gov/air/environmental_tobacco/2005etsfinal.html (accessed 21 Apr 2016).

48 Homa DM, Neff $\amalg$, King BA, et al. Vital signs: disparities in nonsmokers' exposure to secondhand smoke-United States, 1999-2012. MMWR Morb Mortal Wkly Rep 2015;64:103-8.

49 Centers for Disease Control and Prevention. 1986 Surgeon General's report: the health consequences of involuntary smoking. MMWR Morb Mortal Wkly Rep 1986:35:769-70.

50 IARC Handbooks of Cancer Prevention, Tobacco Control, Vol. 13: Evaluating the effectiveness of smoke-free policies [2009: Lyon, France]. https://www.iarc.fr/en/ publications/pdfs-online/prev/handbook13/handbook13.pdf (accessed $21 \mathrm{Apr}$ 2016)

51 Centers for Disease Control and Prevention. State smoke-free laws for worksites, restaurants, and bars-United States, 2000-2010. MMWR Morb Mortal Wkly Rep 2011;60:472-5.

52 Richmond R, Butler T, Wilhelm K, et al. Tobacco in prisons: a focus group study. Tob Control 2009:18:176-82.

53 Lankenau SE. Smoke 'Em If You Got 'Em: cigarette black markets in U.S. Prisons and Jails. Prison J 2001;81:142-61.

54 Sieminska A, Jassem E, Konopa K. Prisoners' attitudes towards cigarette smoking and smoking cessation: a questionnaire study in Poland. BMC Public Health 2006;6:181.

55 Kauffman RM, Ferketich AK, Wewers ME. Tobacco policy in American prisons 2007. Tob Control 2008;17:357-60.

56 Vaughn M, Rolando VD. Legal and policy issues from the Supreme Court's decision on smoking in prisons. Federal Probation 1993;57:34-49.

57 Romero CA, Connell FA. A survey of prison policies regarding smoking and tobacco. J Prison Jail Health 1988;7:27-36.

58 Patrick S, Marsh R. Current tobacco policies in US adult Male prisons. Soc Sci J 2001;38:27-31.

59 Proescholdbell SK, Foley KL, Johnson J, et al. Indoor air quality in prisons before and after implementation of a smoking ban law. Tob Control 2008;17:123-7.

60 Kennedy SM, Davis SP, Thorne SL. Smoke-free policies in U.S. Prisons and jails: A review of the literature. Nicotine Tob Res 2015;17:629-35.

61 Cropsey KL, Kristeller JL. The effects of a prison smoking ban on smoking behavior and withdrawal symptoms. Addict Behav 2005;30:589-94.

62 Kauffman RM, Ferketich AK, Murray DM, et al. Tobacco use by Male prisoners under an indoor smoking ban. Nicotine Tob Res 2011;13:449-56.

63 Lincoln T, Tuthill RW, Roberts CA, et al. Resumption of smoking after release from a tobacco-free correctional facility. J Correct Health Care 2009;15:190-6.

64 Longo DR, Feldman MM, Kruse RL, et al. Implementing smoking bans in American hospitals: results of a national survey. Tob Control 1998;7:47-55.

65 Longo DR, Brownson RC, Kruse RL. Smoking bans in US hospitals. Results of a national survey. JAMA 1995;274:488-91.

66 Williams SC, Hafner JM, Morton DJ, et al. The adoption of smoke-free hospital campuses in the United States. Tob Control 2009;18:451-8.

67 Sullivan DH, Rees MA. Smoking bans in secure psychiatric hospitals and prisons. J Law Med 2014;22:22-30.

68 Burke M. Technical report: smoking policy and treatment in state operated pyschiatric facilities. National Association of State Mental Health Program Directors, Medical Directors Council. 2006. http://www.nasmhpd.org/sites/default/ files/Oct2006\%20Final\%20Report\%20on\%20Smoking\%20Policy\%20and\% 20Treatment\%20atState\%200perated\%20Psychiatric\%20Facilities.pdf (accessed 21 Apr 2016).
69 El-Guebaly N, Cathcart J, Currie S, et al. Public health and therapeutic aspects of smoking bans in mental health and addiction settings. Psychiatr Serv 2002; 53:1617-22.

70 Willemsen MC, Görts CA, Van Soelen P, et al. Exposure to environmental tobacco smoke (ETS) and determinants of support for complete smoking bans in psychiatric settings. Tob Control 2004;13:180-5.

71 Hoffman BF, Eryavec G. Implementation of a no smoking policy on a psychiatric unit. Can J Psychiatry 1992;37:74-5.

72 Shmueli D, Fletcher L, Hall SE, et al. Changes in psychiatric patients' thoughts about quitting smoking during a smoke-free hospitalization. Nicotine Tob Res 2008:10:875-81.

73 Lawn S, Pols R. Smoking bans in psychiatric inpatient settings? A review of the research. Aust N Z J Psychiatry 2005;39:866-85.

74 Prochaska JJ, Gill P, Hall SM. Treatment of tobacco use in an inpatient psychiatric setting. Psychiatr Serv 2004;55:1265-70.

75 Soyster P, Anzai NE, Fromont SC, et al. Correlates of nicotine withdrawal severity in smokers during a smoke-free psychiatric hospitalization. Prev Med. Published Online First: 15 Feb 2016. doi:10.1016/j.ypmed.2016.01.026.

76 Prochaska JJ, Fletcher L, Hall SE, et al. Return to smoking following a smoke-free psychiatric hospitalization. Am J Addict 2006;15:15-22.

77 The National Association of State Alcohol and Drug Abuse Directors. Tobacco Cessation in Substance Use Disorder Treatment Facilities: Single State Agency [or SSA] Tobacco Policies. http://nasadad.org/wp-content/uploads/2015/03/TabaccoCessation-in-Substance-Abuse-Treatment-Facilities-Single-State-Agency-or-SSATabacco-Policies.pdf (accessed 21 Apr 2016).

78 Williams JM, Foulds J, Dwyer M, et al. The integration of tobacco dependence treatment and tobacco-free standards into residential addictions treatment in New Jersey. J Subst Abuse Treat 2005;28:331-40.

79 New York State Office of Alcoholism and Substance Abuse Services. Tobacco-Free Services. https://www.oasas.OT-FSTNP, ny.gov/regs/856.cfm (accessed 21 Apr 2016).

80 Oregon Department of Human Services. Addictions and mental health addictions. http://www.oregon.gov/oha/amh/pages/tobacco-freedom/main.aspx (accessed 21 Apr 2016).

81 Utah Division of Substance Abuse and Mental Health, Recovery Plus Tobacco Project. http://www.dsamh.utah.gov/recovery_plus_tobacco_project (accessed 21 Apr 2016).

82 Muilenburg JL, Laschober TC, Eby LT, et al. Prevalence of and factors related to tobacco ban implementation in substance use disorder treatment programs. Adm Policy Ment Health 2016;43:241-9.

83 Foulds J, Williams J, Order-Connors B, et al. Integrating tobacco dependence treatment and tobacco-free standards into addiction treatment: New Jersey's experience. Alcohol Res Health 2006;29:236-40.

84 Guydish J, Tajima B, Kulaga A, et al. The New York policy on smoking in addiction treatment: findings after 1 year. Am J Public Health 2012;102:e17-25.

85 Pagano A, Guydish J, Le T, et al. Smoking behaviors and attitudes among clients and staff at New York addiction treatment programs following a smoking ban: findings after 5 years. Nicotine Tob Res 2016:18:1274-81.

86 Arangua L, McCarthy WJ, Moskowitz R, et al. Are homeless transitional shelters receptive to environmental tobacco control interventions? Tob Control 2007;16:143-4.

87 Businelle MS, Poonawalla IB, Kendzor DE, et al. Smoking policy change at a homeless shelter: attitudes and effects. Addict Behav 2014:40C:51-6.

88 Vijayaraghavan M, Hurst S, Pierce JP. Implementing tobacco control programs in homeless shelters: a mixed-methods study. Health Promot Pract 2016;17:501-11.

89 Vijayaraghavan M, Hurst S, Pierce JP. A qualitative examination of smoke-free policies and electronic cigarettes among sheltered homeless adults. Am J Health Promot. Published Online First: 11 Nov 2015. doi:10.4278/ajhp.150318-QUAL781.

90 Vijayaraghavan M, Pierce JP. Interest in smoking cessation related to a smoke-free policy among homeless adults. J Community Health 2015;40:686-91.

91 ChangeLab Solutions. Creating Smokefree Policies for Affordable Housing in California. http://www.changelabsolutions.org/publications/ SHS-CA-affordable-housing (accessed 21 Apr 2016).

92 Winickoff JP, Gottlieb M, Mello MM. Regulation of smoking in public housing. N Engl J Med 2010;362:2319-25.

93 U.S. Department of Housing and Urban Development Office of Public and Indian Housing Office of Healthy Homes and Lead Hazard Control. Non-smoking Policies in Public Housing. http://www.hud.gov/offices/pih/publications/notices/09/ pih2009-21.pdf (accessed 21 Apr 2016).

94 U.S. Department of Housing and Urban Development. Instituting Smoke-Free Public Housing. 24 CFR Parts 965 and 966 [Docket No. FR 5597-P-02] RIN 2577-AC97. http://portal.hud.gov/hudportal/documents/huddoc? id=smoke-freepublichousing.pdf (accessed 21 Apr 2016).

95 U.S. Department of Housing and Urban Development. Question and Answers on the HUD's Smoke-free Housing Proposed Rule. http://portal.hud.gov/hudportal/ documents/huddoc?id=finalsmokefreeqa.pdf (accessed 21 Apr 2016). 
96 Drach LL, Pizacani BA, Rohde KL, et al. The acceptability of comprehensive smoke-free policies to low-income tenants in subsidized housing. Prev Chronic Dis 2010;7:A66.

97 Hood NE, Ferketich AK, Klein EG, et al. Individual, social, and environmental factors associated with support for smoke-free housing policies among subsidized multiunit housing tenants. Nicotine Tob Res 2013;15:1075-83.

98 Ballor DL, Henson H, MacGuire K. Support for no-smoking policies among residents of public multiunit housing differs by smoking status. J Community Health 2013:38:1074-80.

99 Rokicki S, Adamkiewicz G, Fang SC, et al. Assessment of Residents' Attitudes and Satisfaction Before and After Implementation of a Smoke-Free Policy in Boston Multiunit Housing. Nicotine Tob Res 2016;18:1282-9.

100 Pizacani BA, Maher JE, Rohde K, et al. Implementation of a smoke-free policy in subsidized multiunit housing: effects on smoking cessation and secondhand smoke exposure. Nicotine Tob Res 2016;18:1282-9.

101 Mills AL, Messer K, Gilpin EA, et al. The effect of smoke-free homes on adult smoking behavior: a review. Nicotine Tob Res 2009;11:1131-41.

102 Cheng KW, Glantz SA, Lightwood JM. Association between smokefree laws and voluntary smokefree-home rules. Am J Prev Med 2015;41:566-72.

103 Borland R, Yong HH, Cummings KM, et al. Determinants and consequences of smoke-free homes: findings from the International Tobacco Control (ITC) Four Country Survey. Tob Control 2006;15(Suppl 3):iii42-50.

104 King BA, Patel R, Babb SD. Prevalence of smokefree home rules-United States, 1992-1993 and 2010-2011. MMWR Morb Mortal Wkly Rep 2014;63:765-9.

105 Messer K, Mills AL, White MM, et al. The effect of smoke-free homes on smoking behavior in the U.S. Am J Prev Med 2008;35:210-6.

106 Gilpin EA, White MM, Farkas AJ, et al. Home smoking restrictions: which smokers have them and how they are associated with smoking behavior. Nicotine Tob Res 1999;1:153-62.

107 King BA, Hyland AJ, Borland R, et al. Socioeconomic variation in the prevalence, introduction, retention, and removal of smoke-free policies among smokers: findings from the International Tobacco Control (ITC) Four Country Survey. Int J Environ Res Public Healt 2011;8:411-34.

108 Mills AL, White MM, Pierce JP, et al. Home smoking bans among U.S. Households with children and smokers opportunities for intervention. Am J Prev Med 2011;41:559-65.

109 Kegler MC, Bundy L, Haardörfer R, et al. A minimal intervention to promote smoke-free homes among 2-1-1 callers: a randomized controlled trial. Am J Public Health 2015;105:530-7.

110 Grana RA, Ling PM, Benowitz N, et al. Electronic cigarettes. Cardiology patient page. Circulation 2014;129:e490-2.

111 King BA, Patel R, Nguyen KH, et al. Trends in Awareness and Use of Electronic Cigarettes Among US Adults, 2010-2013. Nicotine Tob Res 2015;17:219-27.

112 Tan AS, Bigman CA. E-cigarette awareness and perceived harmfulness: prevalence and associations with smoking-cessation outcomes. Am J Prev Med 2014;47:141-9.

113 Dutra LM, Glantz SA. Electronic cigarettes and conventional cigarette use among US adolescents: a cross-sectional study. JAMA Pediatr 2014;168:684.

114 Kalkhoran S, Glantz SA. E-cigarettes and smoking cessation in real-world and clinical settings: a systematic review and meta-analysis. Lancet Respir Med 2016;4:116-28.
115 Grana R, Benowitz N, Glantz SA. E-cigarettes: a scientific review. Circulation 2014;129:1972-86.

116 Grana RA, Popova L, Ling PM. A longitudinal analysis of electronic cigarette use and smoking cessation. JAMA Intern Med 2014;174:812-13.

117 Marynak K, Holmes CB, King BA, et al. State laws prohibiting sales to minors and indoor use of electronic nicotine delivery systems-United States, November 2014. MMWR Morb Mortal Wkly Rep 2014;63:1145-50.

118 Deeming Tobacco Products To Be Subject to the Federal Food, Drug, and Cosmetic Act, as Amended by the Family Smoking Prevention and Tobacco Control Act. https://www.federalregister.gov/articles/2016/05/10/2016-10685/deeming-tobaccoproducts-to-be-subject-to-the-federal-food-drug-and-cosmetic-act-as-amended-bythe (accessed 24 Jun 2016).

119 U.S. Department of Health and Human Services. The Health Consequences of Smoking-50 Years of Progress: A Report of the Surgeon General, 2014. Atlanta, GA http://www.surgeongeneral.gov/library/reports/50-years-of-progress/ (accessed 21 Apr 2016).

$120 \mathrm{Ku}$ L, Bruen BK, Steinmetz E, et al. Medicaid tobacco cessation: big gaps remain in efforts to get smokers to quit. Health Aff (Millwood) 2016;35:62-70.

$121 \mathrm{Xu}$ X, Bishop EE, Kennedy SM, et al. Annual healthcare spending attributable to cigarette smoking: an update. Am J Prev Med 2015;48:326-33.

122 Greene J, Sacks RM, McMenamin SB. The impact of tobacco dependence treatment coverage and copayments in Medicaid. Am J Prev Med 2014;46:331-6.

123 Richard P, West K, Ku L. The return on investment of a Medicaid tobacco cessation program in Massachusetts. PLOS ONE 2012;7:e29665.

124 Land T, Warner D, Paskowsky M, et al. Medicaid coverage for tobacco dependence treatments in Massachusetts and associated decreases in smoking prevalence. PLOS ONE 2010;5:e9770.

125 United States Department of Labor. FAQs about Affordable Care Act Implementation [Part XIX]. http://www.dol.gov/ebsa/faqs/faq-aca19.html (accessed 21 Apr 2016).

126 Singleterry J, Jump Z, DiGiulio A, et al. State medicaid coverage for tobacco cessation treatments and barriers to coverage-United States, 2014-2015. MMWR Morb Mortal Wkly Rep 2015;64:1194-9.

\section{Answers}

1. True

2. True

3. True

4. True

5. True

6. True 